\title{
Comparision of antioxidant and anti-inflammatory activities of enzyme assisted hydrolysate from Ecklonia maxima blades and stipe
}

\author{
Hyo-Geun Lee ${ }^{1}$, Jun-Geon Je ${ }^{1}$, Jin Hwang ${ }^{1}$, Thilina U. Jayawardena ${ }^{1}$, D.P. Nagahawatta ${ }^{1}$, Yu An Lu', \\ Hyun-Soo Kim², Min-Cheol Kang ${ }^{3}$, Dae-Sung Lee ${ }^{2, *}$, You-Jin Jeon ${ }^{1, *}$ \\ 1 Department of Marine Life Science, Jeju National University, Jeju 63243, Korea \\ ${ }^{2}$ Marine Biodiversity Institute of Korea, Seocheon 33362, Korea \\ ${ }^{3}$ Research Group of Food Processing, Korea Food Research Institute, Wanju 55365, Korea
}

\begin{abstract}
Marine brown seaweeds are a source of functional ingredients with various biological properties. They have been used in the food and functional food industries. Brown seaweeds are divided into three parts of blades, stipe, and root. Normally seaweed blades were used as raw materials for biological research. However, there are limited uses on stipes of Ecklonia maxima (E. maxima) depending on the physicochemical, nutritional, and biological properties. Besides, the comparative studies of two structures of E. maxima, blades and stipe didn't discover previously. This study aimed to compare the potent antioxidant and anti-inflammatory activities of the two structures of E. maxima, blades and stipe in vitro studies to increase the utilization of the two structures of E. maxima. The enzyme-assisted hydrolysate from E. maxima showed significant antioxidant and anti-inflammatory activities. Among them, celluclast-assisted hydrolysate from E. maxima blades (EMBC) and viscozyme-assisted hydrolysate from E. maxima stipe (EMSV) expressed significant protection on hydrogen peroxide-induced oxidative stress. Moreover, EMBC and EMSV treatment remarkably reduced nitric oxide production by downregulation of pro-inflammatory cytokine expressions in lipopolysaccharide-stimulated Raw 264.7 cells. Especially EMBC showed strong inhibition on pro-inflammatory cytokine production compared to EMSV. Taken together research findings suggest that EMBC and EMSV possessed potent antioxidant and anti-inflammatory properties and may be utilized as functional ingredients in the food and functional food sectors.
\end{abstract}

Keywords: Anti-inflammatory activity, Antioxidant activity, Brown seaweed, Ecklonia maxima

Received: Mar 20, 2021 Revised: Apr 22, 2021 Accepted: Apr 26, 2021

${ }^{*}$ Corresponding author: You-Jin Jeon

Department of Marine Life Science, Jeju National University, Jeju 63243, Korea

Tel: +82-64-754-3475, Fax: +82-64-756-3493, E-mail: youjinj@jejunu.ac.kr

${ }^{\star}$ Corresponding author: Dae-Sung Lee

Marine Biodiversity Institute of Korea, Seocheon 33362, Korea

Tel: +82-63-219-9457, E-mail: daesung@mabik.re.kr

This is an Open Access article distributed under the terms of the Creative Commons Attribution Non-Commercial License (http://creativecommons.org/licenses/by$\mathrm{nc} / 4.0 /$ ) which permits unrestricted non-commercial use, distribution, and reproduction in any medium, provided the original work is properly cited.

Copyright $\odot 2021$ The Korean Society of Fisheries and Aquatic Science 


\section{Introduction}

Reactive oxygen species (ROS) are chemically reactive materials that can interact with cellular biomolecules, among which are oxygen-containing free radicals, such as peroxyl (ROO·), hydroperoxyl $\left(\mathrm{HO}_{2} \cdot\right)$, alkoxyl (RO·), sulfonyl (ROS·), hydroxyl (OH·), superoxide $\left(\mathrm{O}_{2} \cdot\right)$, thiyl peroxyl (RSOO$\left.\cdot\right)$, and nitric oxide (NO·), and oxidizing agents, including hypochlorous acid ( $\mathrm{HOCl})$, singlet oxide $\left({ }^{1} \mathrm{O}_{2}\right)$, hydrogen peroxide $\left(\mathrm{H}_{2} \mathrm{O}_{2}\right)$, and organic hydroperoxides (ROOH) (Fernando et al., 2016). However, the excessive production of ROS and free radicals cause an imbalance in the oxidant/antioxidant system, resulting in oxidative stress that is, in turn, highly associated with various diseases such as chronic kidney, cardiovascular, and neurodegenerative diseases (Chen et al., 2020; Gyurászová et al., 2020; Lee et al., 2014; Podkowińska \& Formanowicz, 2020; Rekatsina et al., 2020).

Inflammation is a general immunologic defense response that activates specific physiological and pathological conditions in the human body. Normally, it plays crucial role in non-specific immunity, including detection of bacteria, viruses, and chemical stimuli. However, excessive and chronic inflammation can lead to detrimental inflammatory diseases such as diabetes, arthritis, cancer, and cardiovascular and bowel diseases (Libby, 2007). According to previous reports, excessive production of inflammatory mediators and cytokines is detrimental to exacerbated inflammation. Therefore, the reduction of inflammatory mediators and cytokines may be an effective strategy to treat inflammatory diseases.

Ecklonia maxima (E. maxima) is a brown alga belonging to the genus Ecklonia that is mainly found on the southern coast of Cape Town, South Africa (Rothman et al., 2017), representing a major kelp bed that forms seaweed in this region. Bolton et al. reported the distribution and seasonal habitat changes of $E$. maxima in South Africa for over 70 years (Bolton et al., 2012). However, this has not been fully explored, except in an ecological study (Anderson et al., 1997; Bolton \& Levitt, 1985; Ciepiela et al., 2016; Featonby-Smith \& Van Staden, 1984; Feng \& Aldrich, 2004; Kocira et al., 2018; Mayombo et al., 2019; Papenfus et al., 2012; Papenfuss, 1942; Rothman et al., 2006; Rouphael et al., 2017), and biochemical basic analysis of its antioxidant, neuroprotective, and antidiabetic activities (Kannan et al., 2013; Kulkarni et al., 2019; Mwangi et al., 2013; Rengasamy et al., 2013; Wang et al., 2018; Zhou et al., 2019). In recent decades, large-scale biochemical studies were performed to identify the bioactive compounds of E. maxima (Olasehinde et al., 2019;
Zhou et al., 2019). In our previous study, a sulfated polysaccharide from E. maxima showed antioxidant, anti-melanogenesis, and ultraviolet protective activities (Wang et al., 2020). However, most of the previous studies focused on the evaluation of the bioactivity of E. maxima blades or its whole body, and the potential bioactivities of the two main structures of E. maxima (blades and stipe) have not been clarified. Accordingly, the comparative studies of two structures of E. maxima blades and stipe have been urged for industrial application.

Therefore, in the present study, enzyme assisted hydrolysate from the two structure of E. maxima blades and stipe were prepared by enzyme-assisted hydrolyzation and screened for their potential antioxidant and anti-inflammatory activities. We aimed to establish a comparative evaluation of two structure of $E$. maxima blades and stipe for antioxidant and anti-inflammatory activities, which may help increase their use as functional ingredients in the food and functional food industries.

\section{Materials and Methods}

\section{Materials}

Dulbecco's Modified Eagle's Medium (DMEM), Roswell Park Memorial Institute medium (RPMI) 1640, Fetal vobine serum (FBS), penicillin-streptomycin, and trypsin were purchased from gibco (Mississauga, Ontario, Canada). Bicinchoninic acid (BCA) protein assay kit (Thermo Scientific, Pittsburgh, PA USA), bovine serum albumin (Bovogen, VIC, Australia). Barium chloride dihydrate, ethanol, iron (II) sulfate heptahydrate, acetic acid, hydrochloric acid, nitric acid, ammonium sulfate, sodium hydroxide, phenol, and sulfuric acid were purchased from Daejung (Seoul, Korea). Gallic acid, glucose, Folin \& Ciocalteu's phenol reagent, peroxidase, 2',7'-dichlorofluorescein-diacetate (DCF-DA), 3-(4,5-dimethylthiazol-2-yl)-2,5-diphenyltetrazolium bromide (MTT), gum arabic, and lipopolysaccharide (LPS) were purchased from Sigma-Aldrich (St, Louis, MO, USA). Hydrogen peroxide (Junsei, Japan), dimethyl sulfoxide (VWR International, West Chester, PA) were purchased for experiments. Commercial food grade enzymes (Viscozyme $^{\circledR} \mathrm{L}$; Vis, Celluclast ${ }^{\circledR} 1.5 \mathrm{~L}$; Cellu, AMG 300L; AMG, Termammyl 120L; Ter, Ultraflo Max; Ult) were purchased from Novozyme (Bagsvaerd, Copenhagen, Denmark).

\section{Sample preparation}

The E. maxima (E. maxima) was collected and provided from the University of Cape Town, South Africa. The $10 \mathrm{~g}$ of E. max- 
ima blades and stipe were hydrolyzed with carbohydrases (Vis [pH 4.50, $50^{\circ} \mathrm{C}$ ], Cellu [pH 4.50, $50^{\circ} \mathrm{C}$ ], AMG [pH 4.50, $60^{\circ} \mathrm{C}$ ], Ter $\left[\mathrm{pH} 6.00,60^{\circ} \mathrm{C}\right.$ ], Ult $\left.\left[\mathrm{pH} 7.00,60^{\circ} \mathrm{C}\right]\right)$ for $24 \mathrm{~h}$. After $24 \mathrm{~h}$, the mixtures were clarified by centrifugation $(12,298 \times \mathrm{g}, 15 \mathrm{~min}$, $4^{\circ} \mathrm{C}$ ) to remove residue. Then the supernatants were filtered with Whatman filter paper under vacuum. The filtrates were inactivated $\left(100^{\circ} \mathrm{C}, 10 \mathrm{~min}\right)$ and the $\mathrm{pH}$ was neutralized at $\mathrm{pH} 7.00 \mathrm{using}$ $1 \mathrm{M} \mathrm{NaOH}$ solution. Then the enzyme-assistant extracts were stored at $-80^{\circ} \mathrm{C}$ freezer and lyophilized for further experiments.

\section{Proximate composition}

The chemical compositions were analyzed on the enzyme assisted hydrolysate from the two structure of E. maxima, blades and stipe followed the Association of Official Analytic Chemists (AOAC) method (AOAC, 1999). Total polysaccharide contents were determined with the phenol-sulfuric acid analysis which is most applicable to measure the total glucose levels. Glucose was used as a standard (Dubois et al., 1956). The protein contents were measured by Lowry analysis. Bovine serum albumin was used as standard (Waterborg, 2009). The polyphenolic contents were analyzed by the Folin-Ciocalteu method. Gallic acid was used to measure polyphenol contents (Chandler \& Dodds, 1983). The sulfate contents were measured with $\mathrm{BaSO}_{4}$ assay (Dodgson \& Price, 1962).

\section{Monosugar analysis}

The monosugar analysis was performed with modified methods from Kang et al. (2019). The monosugar contents were analyzed by liquid chromatography (HPAEC-PAD system, Dionex, Sunnyvale, CA, USA) equipped with CarboPac PA1 column $(4.5 \mathrm{~mm} \times 50 \mathrm{~mm})$. The analytic samples were hydrolyzed with $4 \mathrm{M}$ of trifluoracetic acid (TFA) and subjected to CarboPac PA1 column. The relative monosugar contents were calculated with standard mixtures containing (Fucose, Rhamnose, Arabinose, Galactose, Glucose, Mannose, Fructose).

\section{Evaluation of hydrogen peroxide scavenging activity}

The potential free radical scavenging activity was determined with the hydrogen peroxide scavenging method (Kim et al., 2014). Briefly, $100 \mu \mathrm{L}$ of the sample solution and $1 \mathrm{M}$ phosphate buffer (PBS) were mixed in a 96-well plate. Then, $20 \mu \mathrm{L}$ of hydrogen peroxide $(10 \mathrm{mM})$ were added to all of the wells and incubated for $5 \mathrm{~min}$. After $5 \mathrm{~min}$ of incubation, $30 \mu \mathrm{L}$ of ABTS (1.25 $\mathrm{mM})$ and peroxidase (1 unit $/ \mathrm{mL}$ ) were added and additionally incubated for $10 \mathrm{~min}$ at $37^{\circ} \mathrm{C}$. The absorbance was measured using the microplate reader (Synergy HT Multi-Detection microplate reader, Bio-Tek, Winooski, VT, USA) at $405 \mathrm{~nm}$.

\section{Cell culture}

Vero cells and Raw 264.7 cells were purchased from the Korean Cell Line Bank (KCLB, Seoul, Korea). The Vero cells were cultured in RPMI medium containing 10\% FBS and 1\% penicillin and streptomycin (P/S). The Raw 264.7 cells were cultured in DMEM medium supplemented with $10 \%$ FBS and $1 \%$ of $\mathrm{P} /$ S. Cells were maintained in the incubator $\left(37^{\circ} \mathrm{C}, 5 \% \mathrm{CO}_{2}\right)$ and periodically sub-cultured every 2 days interval.

\section{Cell viability}

MTT assay was adopted to determine the cytotoxic effect of the tested samples (Lee et al., 2021). Briefly, the cells were seeded in 96 well plates $\left(1 \times 10^{5}\right.$ cells/well $)$ and incubated for $24 \mathrm{~h}$. When the cell confluence was reached $70 \%$, the different concentrations of samples were treated before stimulant induction and incubated for $24 \mathrm{~h}$. After $24 \mathrm{~h}$ of incubation, the MTT stock solution $(2 \mathrm{mg} / \mathrm{mL})$ was added to each well and incubated more an additional $3 \mathrm{~h}$. Following $3 \mathrm{~h}$, the supernatant was discarded, and $200 \mu \mathrm{L}$ of DMSO was added to calculate the amount of formazan contents. The absorbance was measured using microplate reader at $540 \mathrm{~nm}$.

\section{Determination of intracellular ROS scavenging activity in $\mathrm{H}_{2} \mathrm{O}_{2}$ exposed Vero cells}

The intracellular ROS levels were measured by $2^{\prime}, 7^{\prime}$-dichlorofluorescein diacetate (DCF-DA) fluorescent assay as following previous methods described by Kang et al. (2019). Briefly, Vero cells were seeded in a 96 well plate and incubated for $24 \mathrm{~h}$. After $24 \mathrm{~h}$ incubation, the tested samples were treated before 1 $\mathrm{mM}$ of $\mathrm{H} 2 \mathrm{O} 2$ treatment and incubated for $24 \mathrm{~h} .24 \mathrm{~h}$ later the DCF-DA $(500 \mu \mathrm{g} / \mathrm{mL})$ was added to each wells. The fluorescent measurement was detected by microplate reader (Synergy HT Multi-Detection microplatereader, Bio-Tek) at an excitation and emission wavelength of $485 \mathrm{~mm} / 535 \mathrm{~nm}$.

\section{Evaluation of NO production in LPS-stimulated Raw 264.7 cells}

The nitric oxide (NO) production was measured in LPS-stimulated Raw 264.7 cells by Griess assay (Wang et al., 2020). Briefly, Raw 264.7 cells were seeded in a 96 well plate and incubated for $24 \mathrm{~h}$. after $24 \mathrm{~h}$ of incubation, the tested samples were treated before $1 \mu \mathrm{g} / \mathrm{mL}$ of lipopolysaccharide (LPS) treatment and 
incubated more additional $24 \mathrm{~h}$. After $24 \mathrm{~h}$ of incubation, the $100 \mu \mathrm{L}$ of Griess solution was added and the measurement were detected by microplate-reader (Synergy HT Multi-Detection microplate reader, Bio-Tek) at $500 \mathrm{~nm}$.

\section{Accessing of pro-inflammatory cytokine production level in LPS-stimulated Raw 264.7 cells}

A total $1 \times 10^{5}$ cells/wells were incubated and treated with different concentrations $(31.25-250 \mu \mathrm{g} / \mathrm{mL})$ of tested samples before LPS $(1 \mu \mathrm{g} / \mathrm{mL})$ treatment and subsequently incubated for $24 \mathrm{~h}$. After $24 \mathrm{~h}$ of incubation, the cell culture medium was collected to analyze the pro-inflammatory cytokine production. The pro-inflammatory cytokines (IL-6 and TNF- $\alpha$ ) were analyzed with commercial cytokines analysis ELISA kits (R\&D System, Minneapolis, MN, USA).

\section{Statistical analysis}

All data are expressed as the mean \pm SE and the statistical analysis was performed with GraphPad prism (Version5.01; GraphPad Software, San Diego, CA, USA). The significant differences were expressed as follows: ${ }^{*} p<0.05,{ }^{* *} p<0.01,{ }^{* * *} p<0.001,{ }^{* * * *} p$ $<0.0001$ compared with negative control group, ${ }^{\#} p<0.05,{ }^{\# \#} p<$

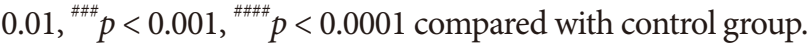

\section{Results}

Measurement of extraction yield, chemical composition and hydrogen peroxide scavenging activity of enzyme assisted hydrolysate from E. maxima blades and stipe.

The extraction yield and chemical composition results give an important nutritional knowledge on enzyme-assisted hydrolysate from E. maxima. The extraction yield, chemical composition, and hydrogen peroxide scavenging activity are summarized in Table 1. Accordingly, the extraction yields were significantly increased in enzyme assisted hydrolysate compared with the water extracts and the extraction yields of the blades were higher than stipe. In addition, high polysaccharide and relatively low polyphenol contents were obserbed in all of the enzyme assisted hydrolysate from E. maxima. Among the enzyme assisted hydrolysates, celluclast assisted hydrolysate from E. maxima blade (EMBC) and viscozyme assisted hydrolysate from E. maxima stipe (EMSV) showed the highest polysaccharide contents (EMBC, $49.64 \pm 0.34 \%$ ) and (EMSV, 20.17 $\pm 0.21 \%$ ) respectively. The potential antioxidant activities of EMBC and EMSV were determined using a hydrogen peroxide scavenging assay. According to the results, the relatively strong hydrogen peroxide scavenging activity was observed in EMBC and EMSV. Therefore, they were chosen for further experiments. The $\mathrm{IC}_{50}$ values were $60.68 \pm 0.01 \mu \mathrm{g} / \mathrm{mL}$ and $79.81 \pm 0.18$ $\mu \mathrm{g} / \mathrm{mL}$ for EMBC and EMSV, respectively.

\section{Monosugar compositions of EMBC and EMSV}

As indicated in Fig. 1, monosugar compositions of EMBC and EMSV indicated that the EMBC were generally composed of

Table 1. Yields, proximate compositions and hydrogen peroxide scavenging activities of enzyme assisted extract from $E$. maxima blades and stipe

\begin{tabular}{|c|c|c|c|c|c|}
\hline Classification & Enzymes & Yield (\%) & Polysaccharide (\%) & Polyphenol (\%) & $\begin{array}{l}\text { Hydrogen peroxide, } \\
\qquad C_{50} \text { value }(\mu \mathrm{g} / \mathrm{mL})\end{array}$ \\
\hline \multirow[t]{6}{*}{ Blades from E. maxima } & - & $27.50 \pm 3.54$ & $21.24 \pm 0.34$ & $0.46 \pm 0.08$ & $77.56 \pm 0.01$ \\
\hline & Vis & $29.00 \pm 1.41$ & $22.06 \pm 0.55$ & $0.52 \pm 0.01$ & $77.52 \pm 0.01$ \\
\hline & Cellu & $29.50 \pm 0.71$ & $49.64 \pm 0.34$ & $0.40 \pm 0.02$ & $60.68 \pm 0.01$ \\
\hline & AMG & $28.50 \pm 0.71$ & $24.40 \pm 0.00$ & $0.45 \pm 0.01$ & $76.47 \pm 0.01$ \\
\hline & Ter & $35.50 \pm 0.71$ & $24.59 \pm 0.14$ & $0.37 \pm 0.06$ & $77.31 \pm 0.01$ \\
\hline & Ult & $31.00 \pm 1.41$ & $26.29 \pm 0.48$ & $0.33 \pm 0.02$ & $75.62 \pm 0.01$ \\
\hline \multirow[t]{6}{*}{ Stipe from E. maxima } & - & $16.00 \pm 1.41$ & $19.92 \pm 0.28$ & $0.15 \pm 0.03$ & $94.18 \pm 0.09$ \\
\hline & Vis & $21.50 \pm 0.71$ & $19.48 \pm 0.07$ & $0.25 \pm 0.05$ & $79.81 \pm 0.18$ \\
\hline & Cellu & $19.50 \pm 0.71$ & $15.89 \pm 0.07$ & $0.20 \pm 0.01$ & $98.82 \pm 0.05$ \\
\hline & AMG & $18.00 \pm 1.41$ & $20.17 \pm 0.21$ & $0.24 \pm 0.01$ & $90.43 \pm 0.03$ \\
\hline & Ter & $16.50 \pm 0.71$ & $19.44 \pm 0.28$ & $0.22 \pm 0.01$ & $117.67 \pm 0.01$ \\
\hline & Ult & $20.50 \pm 2.12$ & $16.96 \pm 0.07$ & $0.43 \pm 0.03$ & $105.99 \pm 0.09$ \\
\hline
\end{tabular}

Vis, viscozyme extract; Cellu, celluclast extract; AMG, acetylated monoglycerides; Ter, termammyl extract; Ult, ultraflo extract. 


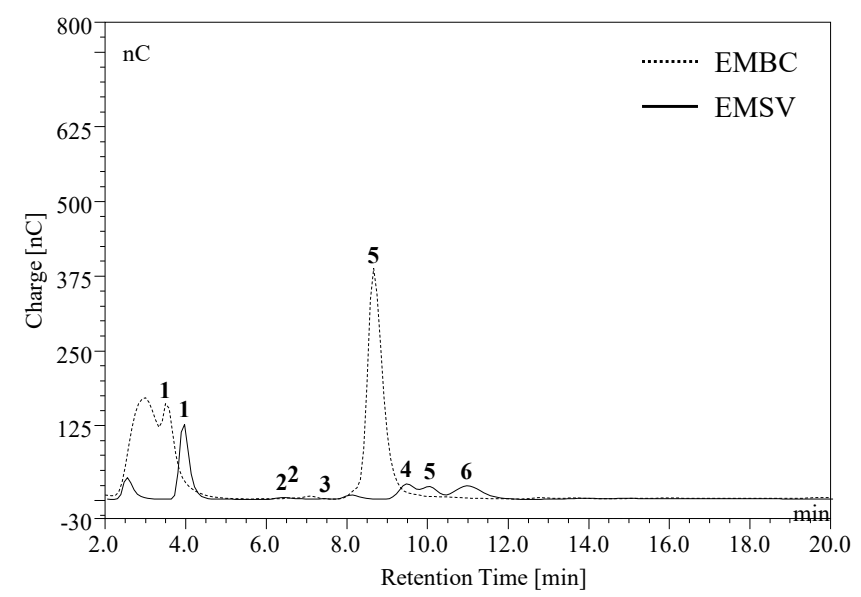

\begin{tabular}{cccc}
\hline NO. & Sugar (\%) & EMBC & EMSV \\
\hline 1 & Fucose & 27.68 & 47.19 \\
2 & Rhamnose & - & 1.64 \\
3 & Arabinose & 0.22 & 0.12 \\
4 & Galactose & - & 15.46 \\
5 & Glucose & 72.10 & 12.91 \\
6 & Mannose & - & 22.69 \\
\hline
\end{tabular}

Fig. 1. Monosugar compositions of EMBC and EMSV. celluclast assisted hydrolysate from E. maxima blade (EMBC), viscozyme assisted hydrolysate from E. maxima stipe (EMSV).

glucose $(72.10 \%)$, fucose $(27.68 \%)$, arabinose $(0.22 \%)$, and EMSV composited of six monosugar such as fucose (47.19\%), mannose (22.69\%), galactose (15.46\%), glucose (12.91\%), rhamnose (1.64\%), and arabinose (0.12\%). Especially the high glucose contents were detected in EMBC, while the EMSV contained high fucose contents.

\section{The protective effect of EMBC and EMSV against $\mathrm{H}_{2} \mathrm{O}_{2}$ exposed Vero cells}

To evaluate the potent antioxidant activities of EMBC and EMSV, the cytotoxicity, $\mathrm{H}_{2} \mathrm{O}_{2}$-induced cell viability and intracellular ROS production were measured in Vero cells (Fig. 2). Fig. 2A demonstrates that the concentration ranges of EMBC and EMSV $(125,250 \mathrm{mg} / \mathrm{mL})$ did not show cytotoxic effects on Vero cells. Thus, the given concentrations (125 and $250 \mu \mathrm{g} /$ $\mathrm{mL}$ ) were chosen for further studies. To evaluate the protective effect of EMBC and EMSV against $\mathrm{H}_{2} \mathrm{O}_{2}$ exposed oxidative stress we performed an MTT and DCF-DA assay to measure the cell viability and intracellular ROS production. As shown in Figs $2 \mathrm{~B}$ and $2 \mathrm{C}$, the cell viability significantly diminished to
$70.10 \pm 1.78 \%$ by $\mathrm{H}_{2} \mathrm{O}_{2}$-exposure. However, EMBC and EMSV remarkably decreased $\mathrm{H}_{2} \mathrm{O}_{2}$-induced cell death. Also, EMBC and EMSV remarkably decreased intracellular ROS production in $\mathrm{H}_{2} \mathrm{O}_{2}$-exposed Vero cells compared to $\mathrm{H}_{2} \mathrm{O}_{2}$-treated group. However, the $125 \mathrm{mg} / \mathrm{mL}$ of EMSV was not effective on $\mathrm{H}_{2} \mathrm{O}_{2}$-induced cell viability and ROS production. These results indicated that EMBC and EMSV possessed significant protection on $\mathrm{H}_{2} \mathrm{O}_{2}$-induced oxidative damages and the potential $\mathrm{ROS}$ scavenging activity was higher in EMBC than EMSV.

\section{The effect of EMBC and EMSV on cell viability and NO production in LPS-stimulated Raw 264.7 cells}

To determine whether the anti-inflammatory effect of EMBC and EMSV, the cytotoxicity, lipopolysaccharide (LPS)-induced cell viability and nitric oxide (NO) production were measured in Raw 264.7 cells. In Fig. 3A showed that the EMBC and EMSV did not express cytotoxicity on Raw 264.7 cells. As shown in Fig. 3B and 3C the cell viability and NO production were significantly up-regulated. While the EMBC and EMSV treatment significantly reduced NO production and increased cell viability in LPS-stimulated Raw 264.7 cells. Accordingly, the results demonstrated that the EMBC and EMSV showed anti-inflammatory activity by suppression of LPS-stimulated NO productions in Raw 264.7 cells.

\section{The effect of EMBC and EMSV against LPS stimulated pro- inflammatory cytokine production}

To elucidate the mechanisms of the anti-inflammatory effect of EMBC and EMSV the pro-inflammatory cytokine productions were analyzed in LPS-stimulated Raw 264.7 cells. As shown in Fig. 4, the LPS stimulation significantly increased inflammatory IL- 6 and TNF- $\alpha$ productions. However, the LPS-activated IL- 6 and TNF- $\alpha$ were significantly lowered with EMBC and EMSV treatment. EMBC showed strong IL-6 inhibitory activity compared to EMSV. These results indicated that EMBC and EMSV showed anti-inflammatory properties by downregulation of the pro-inflammatory cytokine productions in LPS-treated RAW 264.7 cells.

\section{Discussion}

Marine brown seaweeds have been recognized as a traditional food widely consumed in Asian countries, including Korea, Japan, and China (Pereira et al., 2020). Recently, marine natural products have received great attention in the functional food, 
(A)

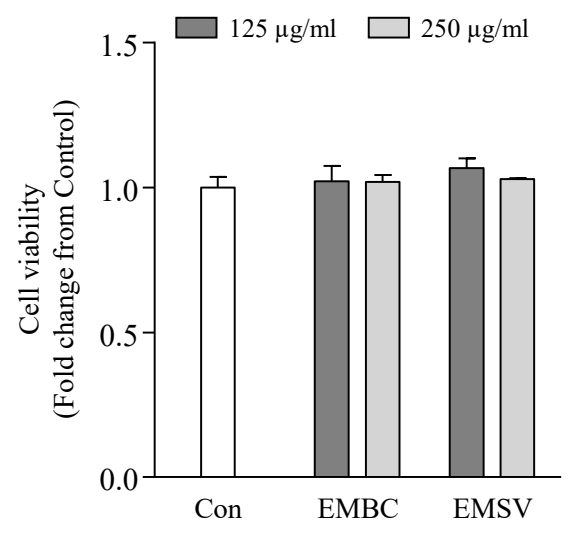

(B)

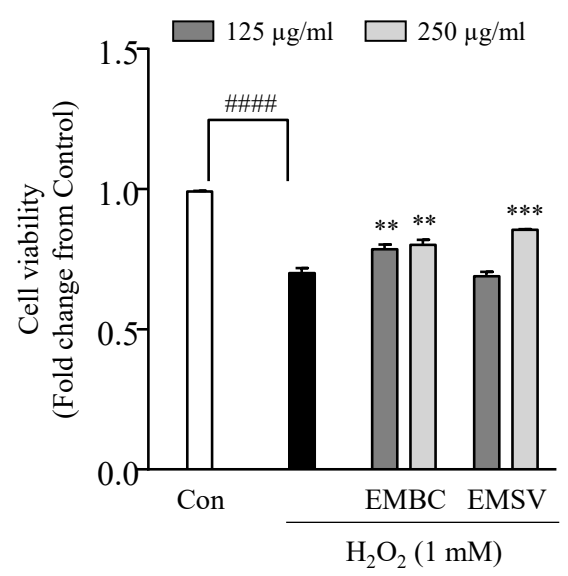

(C)

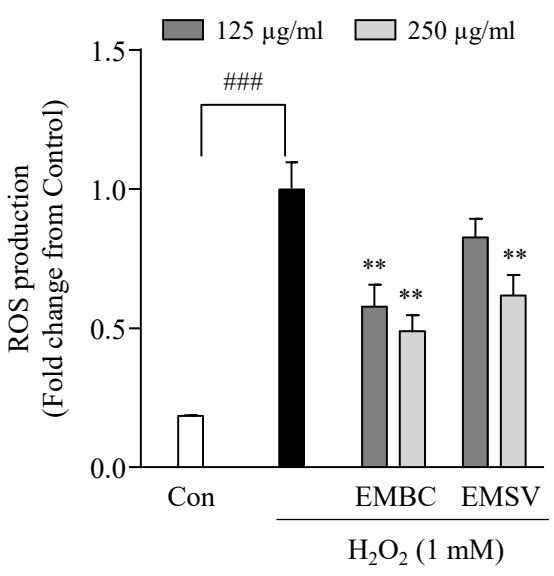

Fig. 2. The cytotoxicity and protective effect of EMBC and EMSV against $\mathrm{H}_{2} \mathrm{O}_{2}$-induced oxidative stress. Cytotoxicity (A), cell viability (B) and ROS production (C) in $\mathrm{H}_{2} \mathrm{O}_{2}$ exposed Vero cells. The experiments were conducted in triplicate and expressed as the mean \pm SE. Significant difference identified at ${ }^{* *} p<0.01,{ }^{* * *} p<0.001$ as compared to $\mathrm{H}_{2} \mathrm{O}_{2}$ group and ${ }^{\# \# \#} p<0.001$ and ${ }^{\# \# \# \#} p<0.0001$ as compared to Control group. ROS, reactive oxygen species. EMBC, celluclast assisted hydrolysate from E. maxima blade; EMSV, viscozyme assisted hydrolysate from E. maxima stipe.

(A)

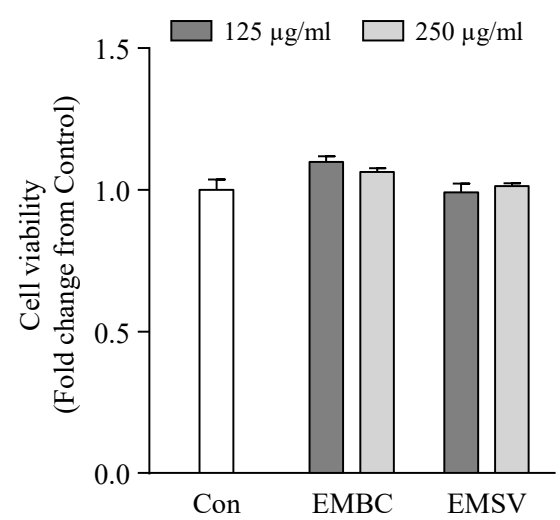

(B)

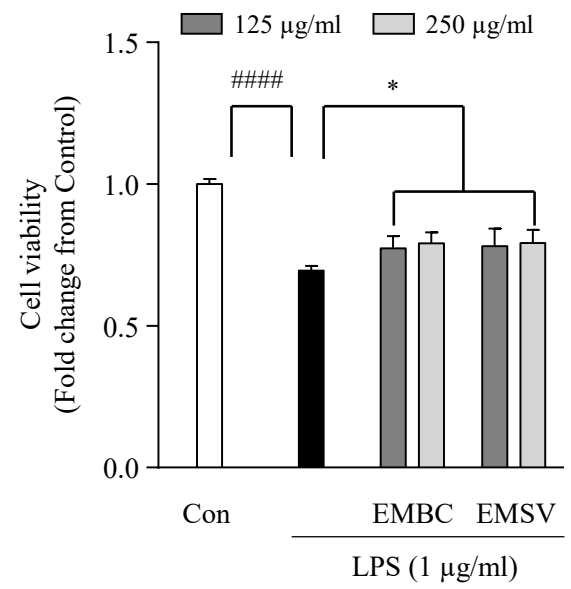

(C)

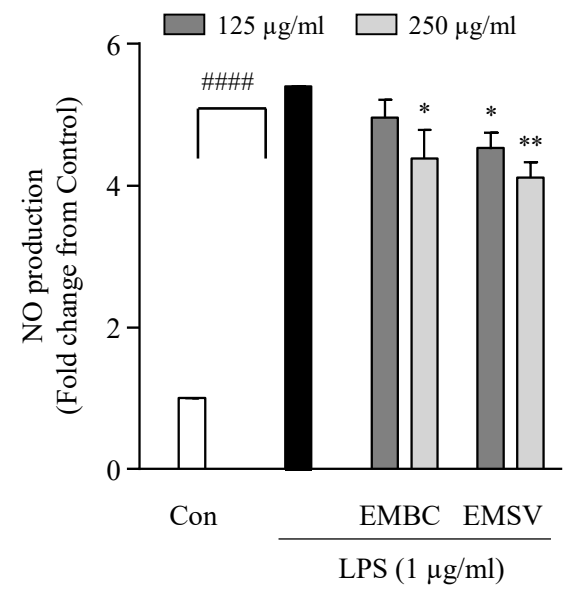

Fig. 3. The potential anti-inflammatory effect of EMBC and EMSV on LPS-stimulated Raw 264.7 cells. Cytotoxicity (A), cell viability (B) and NO production (C) in LPS-stimulated Raw 264.7 cells. The experiments were conducted in triplicate and expressed

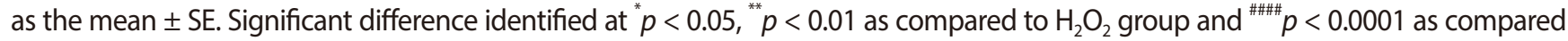
to Control group. LPS, lipopolysaccharide. EMBC, celluclast assisted hydrolysate from E. maxima blade; EMSV, viscozyme assisted hydrolysate from E. maxima stipe.

nutraceutical, and cosmeceutical fields due to their antioxidant and anti-inflammatory properties (Nguyen et al., 2020). There is substantial evidence that marine-derived natural products have a broad range of biological activities (Carroll et al., 2020).
Indeed, marine organisms are renowned for their biological and nutritional richness, comprising polysaccharides, polyphenols, fatty acids, lipids, peptides, essential vitamins, and minerals, which exhibit valuable proprieties including antidiabetic, an- 
(A)
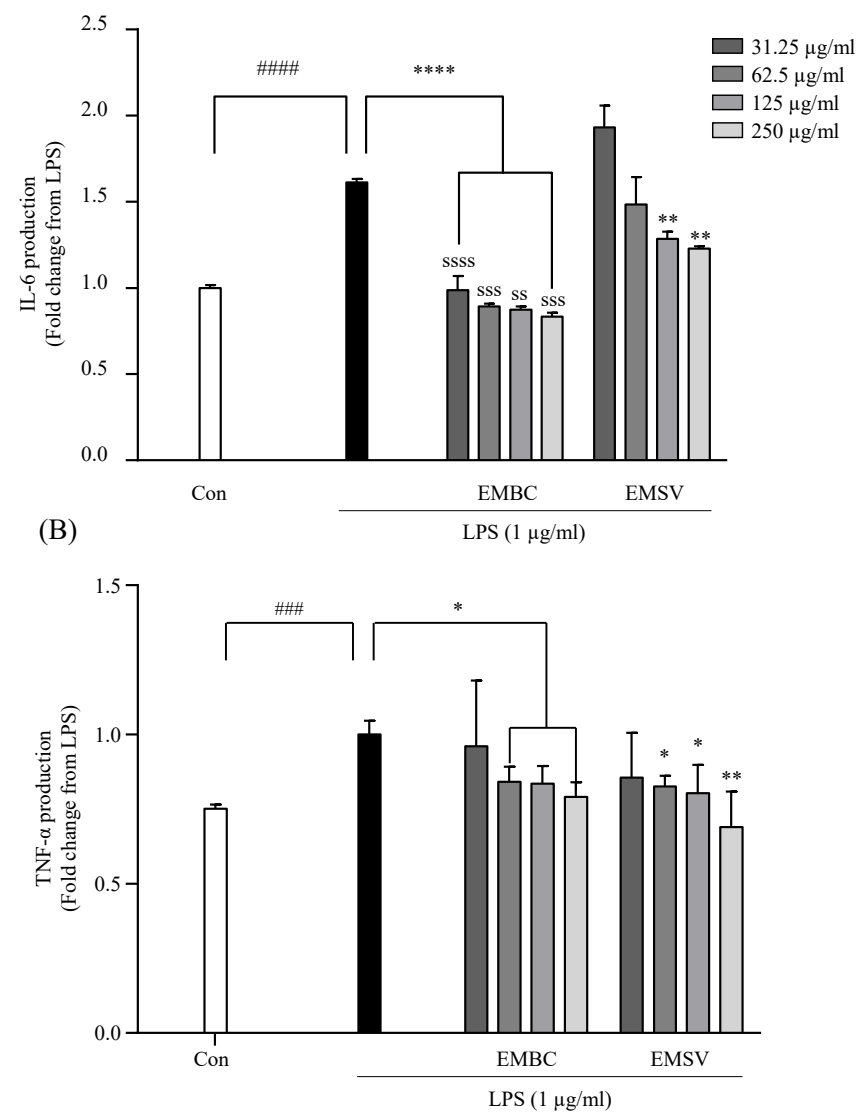

Fig. 4. The EMBC and EMSV suppress the LPS-stimulated inflammatory cytokine production in Raw $\mathbf{2 6 4 . 7}$ cells. The inflammatory IL-6 (A) and TNF-a (B) production in LPS activated Raw 264.7 cells. The experiments were conducted in triplicate and expressed as the mean $\pm \mathrm{SE}$. Significant difference identified at $p<0.05, \quad p<0.01, \quad p<0.0001$ as compared to $\mathrm{H}_{2} \mathrm{O}_{2}$ group

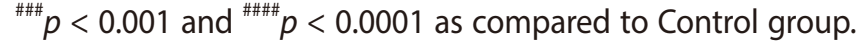
LPS, lipopolysaccharide. EMBC, celluclast assisted hydrolysate from E. maxima blade; EMSV, viscozyme assisted hydrolysate from E. maxima stipe.

tihypertensive, anti-inflammatory, antioxidant, and antiviral activities (Fernando et al., 2017; Peñalver et al., 2020). Hence, these functional ingredients from seaweeds have potential health benefits for human cardiovascular and chronic diseases (Cardoso et al., 2015; Lordan et al., 2011). Further, they have been used in drug discovery for the development of alternative strategies to synthetic medicine, which is often accompanied by undesirable adverse effects. Several different types of marine-derived bioactive compounds have been industrially discovered and commercialized (Pereira et al., 2019), with pre-clinical and clinical trials being performed on numerous marine-derived bioactive compounds (Newman \& Cragg, 2004).

The present study investigated the potential antioxidant and anti-inflammatory properties of enzyme-assisted hydrolysate from EMBC and stipe (EMSV) to determine their relative antioxidant and anti-inflammatory activities. Enzymatic hydrolysis was carried out using different carbohydrases, including Viscozyme, Celluclast, AMG, Termammyl, and Ultraflo. According to the results, the enzymatic extraction yields were higher in the blades than in the stipe. Further, the total polysaccharide content was slightly higher in the blades than in the stipe. Monosaccharide analysis revealed that EMBC and EMSV consist of fucose, arabinose, and glucose contents. Especially the higher fucose content was observed in EMSV and highest glucose content was detected in EMBC respectively. In previous publications indicated that the fucose rich hydrolysates highly attribute to their bioactivities especially antixodant and anti-inflammatory activities and Castro et al. (2014) also reported the potential antioxidant and anti-inflammatory activities of fucose containing sulfated polysaccharide from Lobophora variegata (Castro et al., 2014).

Each of the five enzyme-assisted hydrolysate obtained from E. maxima blades and stipe had the strong hydrogen peroxide scavenging activity. Among them, EMBC and EMSV showed excellent hydrogen peroxide scavenging activity. In addition, it has significant protection against $\mathrm{H} 2 \mathrm{O} 2$ induced oxidative damage in Vero cells. However, there is no significant difference in antioxidant activities between EMBC and EMSV. Moreover, the EMBC and EMSV significantly downregulated the NO production in LPS-stimulated Raw 264.7 cells by downregulation of pro-inflammatory cytokine (IL-6 and TNF- $\alpha$ ) production. In particular, EMBC considerably inhibited the IL- 6 production compared to EMSV. The pro-inflammatory cytokines such as IL-6 and TNF-a involve the initiation and inflammatory responses. Contrary to the LPS is a stimulator of immune responses which induce macrophage activation and cytokine production. Therefore the modulation of IL- 6 and TNF- $\alpha$ production may be an effective strategy to ameliorate the excessive immune responses against LPS exposure in Raw 264.7 cells. Taken together, these results indicated that the enzyme assisted hydrolysate from the two structures of E. maxima blades and stipe are potential candidate for the development of antioxidant and anti-inflammatory materials and could be used as a functional ingredient in functional food industry. 


\section{Competing interests}

No potential conflict of interest relevant to this article was reported.

\section{Funding sources}

This research was financially supported by a grant from the Marine Biotechnology program (20170488) funded by the Ministry of Oceans and Fisheries, Korea.

\section{Acknowledgements}

Not applicable.

\section{Availability of data and materials}

Upon reasonable request, the datasets of this study can be available from the corresponding author.

\section{Ethics approval and consent to participate}

This article does not require IRB/IACUC approval because there are no human and animal participants.

\section{ORCID}

Hyo-Geun Lee

Jun-Geon Je

Jin Hwang

Thilina U. Jayawardena

D.P. Nagahawatta

Yu An Lu

Hyun-Soo Kim

Min-Cheol Kang

Dae-Sung Lee

You-Jin Jeon

\section{References}

AOAC. Official methods of analysis. 17th ed. Gaithersburg, MD: Association of Official Analytical Chemists; 1999.

Anderson RJ, Carrick P, Levitt GJ, Share A. Holdfasts of adult kelp Ecklonia maxima provide refuges from grazing for recruitment of juvenile kelps. Mar Ecol Prog Ser. 1997; 159:265-73.

Bolton JJ, Anderson RJ, Smit AJ, Rothman MD. South African kelp moving eastwards: the discovery of Ecklonia maxima (Osbeck) Papenfuss at De Hoop Nature Reserve on the south coast of South Africa. Afr J Mar Sci. 2012;34:147-51.

Bolton JJ, Levitt GJ. Light and temperature requirements for growth and reproduction in gametophytes of Ecklonia maxima (Alariaceae: Laminariales). Mar Biol. 1985;87:131-5.

Cardoso SM, Pereira OR, Seca AML, Pinto DCGA, Silva AMS. Seaweeds as preventive agents for cardiovascular diseases: from nutrients to functional foods. Mar Drugs. 2015;13:6838-65.

Castro LSEPW, Pinheiro TS, Castro AJG, Dore CMPG, da Silva NB, Alves MGCF, et al. Fucose-containing sulfated polysaccharides from brown macroalgae Lobophora variegata with antioxidant, anti-inflammatory, and antitumoral effects. J Appl Phycol. 2014;26:1783-90.

Carroll AR, Copp BR, Davis RA, Keyzers RA, Prinsep MR. Marine natural products. Nat Prod Rep. 2020;37:175-223.

Chandler SF, Dodds JH. The effect of phosphate, nitrogen and sucrose on the production of phenolics and solasodine in callus cultures of Solanum laciniatum. Plant Cell Rep. $1983 ; 2: 205-8$.

Chen Z, Tian R, She Z, Cai J, Li H. Role of oxidative stress in the pathogenesis of nonalcoholic fatty liver disease. Free Radic Biol Med. 2020;152:116-41.

Ciepiela GA, Godlewska A, Jankowska J. The effect of seaweed Ecklonia maxima extract and mineral nitrogen on fodder grass chemical composition. Environ Sci Pollut Res. 2016;23:2301-7.

Dodgson KS, Price RG. A note on the determination of the ester sulphate content of sulphated polysaccharides. Biochem J. 1962;84:106-10.

Dubois M, Gilles KA, Hamilton JK, Rebers PA, Smith F. Colorimetric method for determination of sugars and related substances. Anal Chem. 1956;28:350-6.

Featonby-Smith BC, Van Staden J. Identification and seasonal variation of endogenous cytokinins in Ecklonia maxima (Osbeck) Papenf. Bot Mar. 1984;27:527-30.

Feng D, Aldrich C. Adsorption of heavy metals by biomaterials derived from the marine alga Ecklonia maxima. Hydrometallurgy. 2004;73:1-10.

Fernando IPS, Sanjeewa KKA, Samarakoon KW, Lee WW, Kim HS, Kim EA, et al. FTIR characterization and antioxidant activity of water soluble crude polysaccharides of Sri Lankan marine algae. Algae. 2017;32:75-86.

Fernando IPS, Kim M, Son KT, Jeong Y, Jeon YJ. Antioxidant activity of marine algal polyphenolic compounds: a mechanistic approach. J Med Food. 2016;19:615-28.

Gyurászová M, Gurecká R, Bábíčková J, Tóthová L. Oxidative stress in the pathophysiology of kidney disease: implica- 
tions for noninvasive monitoring and identification of biomarkers. Oxid Med Cell Longev. 2020;2020:5478708.

Kannan RRR, Aderogba MA, Ndhlala AR, Stirk WA, Van Staden J. Acetylcholinesterase inhibitory activity of phlorotannins isolated from the brown alga, Ecklonia maxima (Osbeck) Papenfuss. Food Res Int. 2013;54:1250-4.

Kang MC, Lee HG, Choi HD, Jeon YJ. Antioxidant properties of a sulfated polysaccharide isolated from an enzymatic digest of Sargassum thunbergii. Int J Biol Macromol. 2019;132:142-9.

Kim EA, Lee SH, Ko CI, Cha SH, Kang MC, Kang SM, et al. Protective effect of fucoidan against AAPH-induced oxidative stress in zebrafish model. Carbohydr Polym. 2014;102:185-91.

Kocira A, Świeca M, Kocira S, Złotek U, Jakubczyk A. Enhancement of yield, nutritional and nutraceutical properties of two common bean cultivars following the application of seaweed extract (Ecklonia maxima). Saudi J Biol Sci. 2018;25:563-71.

Kulkarni MG, Rengasamy KRR, Pendota SC, Gruz J, Plačková L, Novák O, et al. Bioactive molecules derived from smoke and seaweed Ecklonia maxima showing phytohormone-like activity in Spinacia oleracea L. New Biotechnol. 2019;48:83-9.

Lee HG, Kim HS, Oh JY, Lee DS, Yang HW, Kang MC, et al. Potential antioxidant properties of enzymatic hydrolysates from Stichopus japonicus against hydrogen peroxide-induced oxidative stress. Antioxidants. 2021;10:110.

Lee YH, Cheng FY, Chiu HW, Tsai JC, Fang CY, Chen CW, et al. Cytotoxicity, oxidative stress, apoptosis and the autophagic effects of silver nanoparticles in mouse embryonic fibroblasts. Biomaterials. 2014;35:4706-15.

Libby P. Inflammatory mechanisms: the molecular basis of inflammation and disease. Nutr Rev. 2007;65:S140-6.

Lordan S, Ross RP, Stanton C. Marine bioactives as functional food ingredients: potential to reduce the incidence of chronic diseases. Mar Drugs. 2011;9:1056-100.

Mayombo NAS, Majewska R, Smit AJ. Diatoms associated with two South African kelp species: Ecklonia maxima and Laminaria pallida. Afr J Mar Sci. 2019;41:221-9.

Mwangi HM, Van Der Westhuizen J, Marnewick J, Mabusela WT, Kabanda MM, Ebenso EE. Isolation, identification and radical scavenging activity of phlorotannin derivatives from brown algae, Ecklonia maxima: an experimental and theoretical study. Free Radic Antioxid. 2013;3:S1-10.

Newman DJ, Cragg GM. Marine natural products and related compounds in clinical and advanced preclinical trials. J Nat Prod. 2004;67:1216-38.

Nguyen TT, Heimann K, Zhang W. Protein recovery from underutilised marine bioresources for product development with nutraceutical and pharmaceutical bioactivities. Mar Drugs. 2020;18:391.

Olasehinde TA, Olaniran AO, Okoh AI. Macroalgae as a valuable source of naturally occurring bioactive compounds for the treatment of Alzheimer's disease. Mar Drugs. 2019;17:609.

Papenfus HB, Stirk WA, Finnie JF, Van Staden J. Seasonal variation in the polyamines of Ecklonia maxima. Bot Mar. 2012;55:539-46.

Papenfuss GF. Studies of South African Phaeophyceae. I. Ecklonia maxima, Laminaria pallida, Macrocystis pyrifera. Am J Bot. 1942;29:15-24.

Peñalver R, Lorenzo JM, Ros G, Amarowicz R, Pateiro M, Nieto $\mathrm{G}$. Seaweeds as a functional ingredient for a healthy diet. Mar Drugs. 2020;18:301.

Pereira F. Have marine natural product drug discovery efforts been productive and how can we improve their efficiency? Expert Opin Drug Discov. 2019;14:717-22.

Pereira SA, Kimpara JM, Valenti WC. A bioeconomic analysis of the potential of seaweed Hypnea pseudomusciformis farming to different targeted markets. Aquac Econ Manag. 2020;24:507-25.

Podkowińska A, Formanowicz D. Chronic kidney disease as oxidative stress- and inflammatory-mediated cardiovascular disease. Antioxidants. 2020;9:752.

Rekatsina M, Paladini A, Piroli A, Zis P, Pergolizzi JV, Varrassi G. Pathophysiology and therapeutic perspectives of oxidative stress and neurodegenerative diseases: a narrative review. Adv Ther. 2020;37:113-39.

Rengasamy KRR, Aderogba MA, Amoo SO, Stirk WA, Van Staden J. Potential antiradical and alpha-glucosidase inhibitors from Ecklonia maxima (Osbeck) Papenfuss. Food Chem. 2013;141:1412-5.

Rothman MD, Anderson RJ, Smit AJ. The effects of harvesting of the South African kelp (Ecklonia maxima) on kelp population structure, growth rate and recruitment. Paper presented at: 18th International Seaweed Symposium; 2004 Jun 20-25; Bergen, Norway.

Rothman MD, Bolton JJ, Stekoll MS, Boothroyd CJT, Kemp FA, Anderson RJ. Geographical variation in morphology of the two dominant kelp species, Ecklonia maxima and Laminar- 
ia pallida (Phaeophyceae, Laminariales), on the west coast of Southern Africa. J Appl Phycol. 2017;29:2627-39.

Rouphael Y, De Micco V, Arena C, Raimondi G, Colla G, De Pascale S. Effect of Ecklonia maxima seaweed extract on yield, mineral composition, gas exchange, and leaf anatomy of zucchini squash grown under saline conditions. J Appl Phycol. 2017;29:459-70.

Wang L, Jayawardena TU, Yang HW, Lee HG, Jeon YJ. The potential of sulfated polysaccharides isolated from the brown seaweed Ecklonia maxima in cosmetics: antioxidant, anti-melanogenesis, and photoprotective activities. Antioxidants. 2020;9:724.

Wang L, Jeon YJ, Kim JI. In vitro and in vivo anti-inflammatory activities of a sterol-enriched fraction from freshwater green alga, Spirogyra sp. Fish Aquat Sci. 2020;23:1-9.

Wang J, Zheng J, Huang C, Zhao J, Lin J, Zhou X, et al. Eckmaxol, a phlorotannin extracted from Ecklonia maxima, produces anti- $\beta$-amyloid oligomer neuroprotective effects possibly via directly acting on glycogen synthase kinase $3 \beta$. ACS Chem Neurosci. 2018;9:1349-56.

Waterborg JH. The Lowry method for protein quantitation. In: Walker JM, editor. The protein protocols handbook. New York, NY : Humana Press; 2009. p. 7-10.

Zhou X, Yi M, Ding L, He S, Yan X. Isolation and purification of a neuroprotective phlorotannin from the marine algae Ecklonia maxima by size exclusion and high-speed counter-current chromatography. Mar Drugs. 2019;17:212. 